Gut, 1983, 24, 751-755

\title{
Effect of polyunsaturated phosphatidylcholine on immune mediated hepatocyte damage
}

\author{
JAMES NEUBERGER, J. E HEGARTY, A L W F EDDLESTON, \\ AND ROGER WILLIAMS \\ From the Liver Unit, King's College Hospital and Medical School, Denmark Hill, London
}

SUMMARY Studies were carried out to investigate the mechanisms underlying the reduction of hepatocellular necrosis observed when polyunsaturated phosphatidylcholine was administered to patients with HBsAg negative chronic active hepatitis. After oral administration of the agent, the susceptibility of rabbit hepatocytes to both antibody dependent cell mediated cytotoxicity and mitogen induced lymphocyte cytotoxicity was substantially reduced. Short term in vitro incubation of either the hepatocytes or lymphocytes with polyunsaturated phosphatidylcholine had no effect on antibody dependent cell mediated cytotoxicity. As it has been shown that orally administered polyunsaturated phosphatidylcholine can be incorporated into the liver cell membrane, it is possible that polyunsaturated phosphatidylcholine exerts its effect by blocking the interaction between immune effector cells and hepatocytes.

In a double-blind, placebo controlled randomised trial, polyunsaturated phosphatidylcholine $(1.8 \mathrm{~g} /$ day) was used as adjunctive therapy in 30 patients with HBsAg negative chronic active hepatitis who were inadequately controlled on conventional doses of corticosteroids and azathioprine. ${ }^{1}$ Treatment with polyunsaturated phosphatidylcholine was associated with a significant improvement in the severity of the disease as assessed histologically. A number of uncontrolled trials have shown that this agent is of therapeutic benefit in the treatment of a variety of hepatic disorders including drug induced hepatitis, chronic persistent hepatitis, and cirrhosis. ${ }^{2}$

One of the putative mechanisms to account for the hepatocellular damage in $\mathrm{HBsAg}$ negative chronic active hepatitis is an antibody dependent cell mediated cytotoxicity reaction in which 'killer' lymphocytes bind to and lyse the antibody coated target cells. ${ }^{34}$ Experimental observation in both animals and man have shown that polyunsaturated phosphatidylcholine, a highly unsaturated phosphatidylcholine species extracted from soya beans, mainly dilinoleoyl phosphatidylcholine, is incorporated into hepatocyte plasma membranes. ${ }^{5} 6$ Thus it is possible that the therapeutic action of polyunsaturated phosphatidylcholine is mediated by

Address for correspondence: Dr J Neuberger, Liver Unit, King's College Hospital, Denmark Hill, London, SE5 9RS.

Received for publication 29 December 1982 affecting the binding of antibody to the hepatocyte or by interfering with the interaction of the effector cells with the target cells. In the present study, the effect of polyunsaturated phosphatidylcholine on these possible interactions was studied in vitro using a microcytotoxicity technique.

\section{Methods}

SERA

Sera from 10 patients with chronic active hepatitis were used for the in vitro cytotoxicity assay. In each case the diagnosis had been made according to internationally agreed criteria. ${ }^{7}$ Symptoms had been present for periods ranging from six months to four and a half years, median 18 months.

The patients (nine women, one man, median age 48 years, range 25-52 years) gave no history of exposure to known hepatoxic agents and all admitted to a daily ethanol intake of less than $20 \mathrm{~g}$. All patients were Caucasians. Serum from three patients was taken before the introduction of therapy and from seven who were in relapse after attempted withdrawal of prednisolone therapy, two of whom were still receiving prednisolone ( 2 and 2.5 $\mathrm{mg}$ daily). All seven had been taking azathioprine before reduction of the corticosteroids. At the time of testing the serum transferases were raised, range 220-700 IU/1, median 380 IU/1 (upper limit of normal $40 \mathrm{IU} / \mathrm{l})$, with overt piecemeal necrosis on 
histological examination of the liver biopsy. One patient had suffered a relapse previously. All patients were negative for serum $\mathrm{HBsAg}$, antiHBs and anti-HBc (using Ausria, Ausab, and Corab respectively (Abbott Laboratories)). Sera were stored at $-20^{\circ} \mathrm{C}$ and immediately before use were heated at $37^{\circ} \mathrm{C}$ for 30 minutes to inactivate complement.

\section{PREPARATION OF HEPATOCYTES}

Female New Zealand white rabbits (weight 2-2.5 $\mathrm{kg}$ ) were given polyunsaturated phosphatidylcholine $100 \mathrm{mg} / \mathrm{kg} /$ day (Nattermann and Cie. GmbH, Cologne) emulsified in their drinking water throughout the day for six weeks. Control rabbits were given water. The rabbits were killed by intravenous injection of pentabarbitone and the liver removed in a sterile fashion. Isolated hepatocytes were prepared by enzyme digestion using collagenase, as described elsewhere. ${ }^{3}$ After washing, isolated hepatocytes were seeded into microculture test wells $(100$ cells/well $)$ and incubated overnight to allow the cells to adhere to the plastic.

\section{ANTIBODY DEPENDENT CELL MEDIATED CYTOTOXICITY REACTION (ADCC)}

Sera from patients were diluted 1 in 100 in RPMI1640 with glutamine (Gibco Laboratories) and $10 \mu \mathrm{l}$ added to at least 10 wells. The microtest plates were incubated for two hours at $37^{\circ} \mathrm{C}$ to allow any antibody present in the serum to react with normal rabbit liver cell antigens on the surface of the hepatocytes. In control wells the hepatocytes were incubated with $10 \%$ fetal calf serum (Gibco) in RPMI-1640. After washing of the hepatocytes, lymphocytes isolated from normal healthy individuals (aged 24-36 years), prepared by dextran sedimentation, cotton wool incubation, and FicollTriosil centrifugation ${ }^{4}$ were added in a ratio of 100 lymphocytes per hepatocyte. After a further 36 hours' incubation the percentage cytotoxicity was determined by comparing the number of hepatocytes remaining in the test wells with those in control wells. ${ }^{4}$ The upper limit of normal $(28 \%)$ was calculated as the mean + two standard deviations from the mean using 30 normal sera.

\section{SHORT-TERM INCUBATION OF HEPATOCYTES AND LYMPHOCYTES WITH POLYUNSATURATED PHOSPHATIDYLCHOLINE}

To determine whether polyunsaturated phosphatidylcholine exerts its effect by interference with the reaction between either the antibody and the hepatocyte or the effector lymphocyte and the antibody coated hepatocyte, short-term incubation studies were performed. The hepatocytes were isolated from normal rabbits and seeded into microculture test wells; after overnight incubation $0.1 \mu \mathrm{g}$ polyunsaturated phosphatidylcholine homogenised in $10 \mu \mathrm{l}$ of RPMI-1640 was added. After 18 hours' incubation, the plates were washed and the hepatocytes used in the cytotoxicity assay as described above. In the second series of experiments, normal lymphocytes were isolated as described above, and incubated in $1 \%$ polyunsaturated phosphatidylcholine in a medium of $10 \%$ fetal calf serum in RPMI-1640 in an atmosphere of $83 \%$ nitrogen, $12 \%$ oxygen, and $5 \%$ carbon dioxide to 18 hours at $37^{\circ} \mathrm{C}$. The cells were washed and then used in the cytotoxicity assay as before.

\section{MITOGEN INDUCED CYTOTOXICITY}

Lymphocytes were isolated from six healthy individuals (aged 26-36 years). Lymphocytes from each individual were then divided into two aliquots at a concentration of $5 \times 10^{6}$ cells $/ \mathrm{ml}$ in $10 \%$ fetal calf serum. To one culture tube was added phytohaemagglutinin (Sigma Reagents Ltd) $5 \mu \mathrm{g} / 10^{6}$ cells, and the tubes were then incubated in $83 \%$ nitrogen, $12 \%$ oxygen, and $5 \%$ carbon dioxide at $37^{\circ} \mathrm{C}$ for 48 hours.

After washing three times, the lymphocytes were then added to the hepatocytes in a ratio of 400 lymphocytes per hepatocyte. After a further 36 hours' incubation the number of adherent hepatocytes were counted and the percentage cytotoxicity determined.

\section{STATISTICS}

Significant values were calculated using Wilcoxon's rank test.

\section{Results}

\section{ANTIBODY DEPENDENT CELL MEDIATED}

CYTOTOXICITY

All 10 sera from the patients with chronic active hepatitis induced significant cytotoxicity to hepatocytes isolated from control rabbits (median 49\%, range $31-52 \%$ ). In contrast, no significant cytotoxicity was observed after the same sera were incubated with hepatocytes isolated from rabbits pretreated with polyunsaturated phosphatidylcholine for six weeks (median $12 \%$, range $0-21 \%$, $\mathrm{p}<0.01$, Fig. 1). Short-term incubation of the hepatocytes with polyunsaturated phosphatidylcholine in vitro did not lead to any alteration in the percentage cytotoxicity induced by the sera (median $34 \%$, range $31-58 \%$, for six sera before treatment and median $37 \%$, range $34-56 \%$, after treatment). Incubation of the lymphocytes with polyunsaturated 


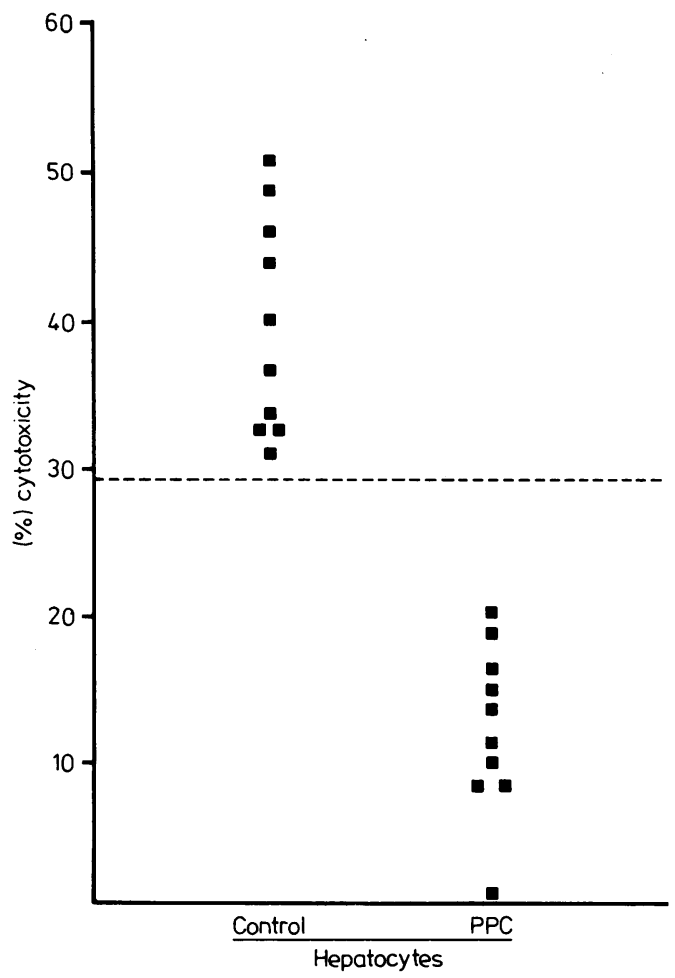

Fig. 1 Lymphocyte cytotoxicity to isolated hepatocytes from control and polyunsaturated phosphatidylcholine treated rabbits, induced by sera from patients with chronic active hepatitis.

phosphatidylcholine also had no effect on cytotoxicity (median 36\%, range $32-48 \%$, before treatment and median $35 \%$, range $30-41 \%$, after treatment). The seeding efficiency of the treated and untreated hepatocytes was similar, showing that the adherence of the hepatocytes to the tissue culture plastic was not affected by treatment with polyunsaturated phosphatidylcholine.

\section{MITOGEN INDUCED LYMPHOCYTE CYTOTOXICITY}

None of the lymphocytes from each of six controls were directly cytotoxic to hepatocytes isolated from either the control or polyunsaturated phosphatidylcholine treated rabbits (Fig. 2). In contrast, after treatment with phytohaemagglutinin, lymphocytes from five of the six individuals were directly cytotoxic to untreated hepatocytes (median $48 \%$, range $32-54 \%$, for the five sera giving significant cytotoxicity). The results of the cytotoxicity of the lymphocytes from the sixth individual were excluded from the analysis as these lymphocytes did not respond to phytohaemagglutinin and therefore no

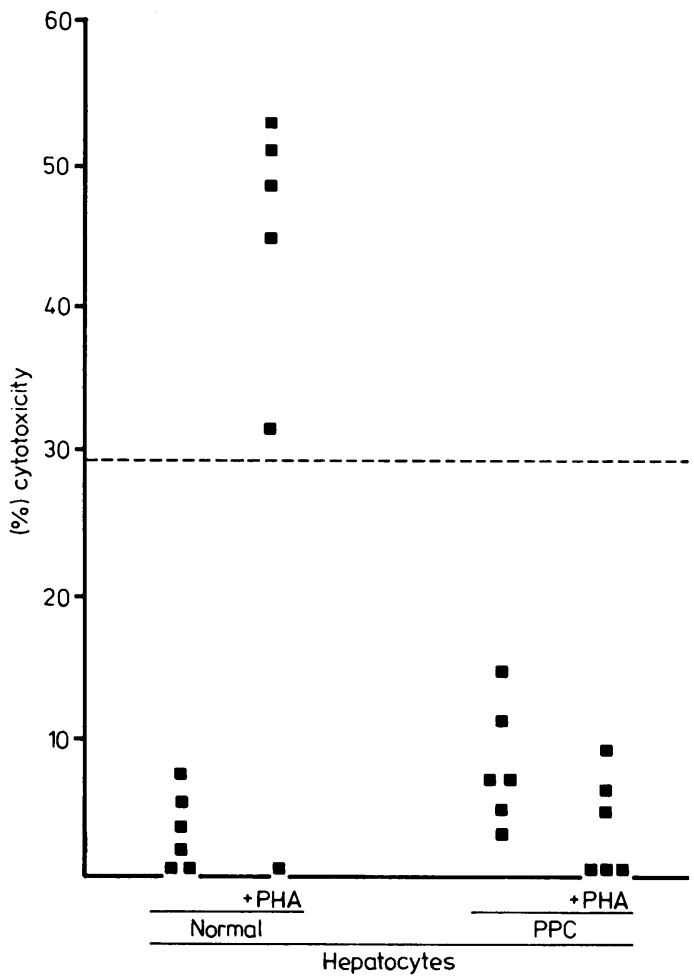

Fig. 2 Direct cytotoxicity to untreated and mitogen induced lymphocytes to isolated hepatocytes from control and polyunsaturated phosphatidylcholine treated rabbits. $P H A=$ phytohaemagglutinin.

effect of polyunsaturated phosphatidylcholine in the abolition of cytotoxicity would be shown. In contrast, when the hepatocytes isolated from rabbits treated with polyunsaturated phosphatidylcholine were used, none of the mitogen stimulated lymphocytes was directly cytotoxic (median $5 \%$, range $0-10 \%, \mathrm{p}<0.01)$.

\section{Discussion}

Extrapolation of the in vitro studies reported here would suggest that the mode of action of polyunsaturated phosphatidylcholine in vivo in patients with chronic active hepatitis may be to reduce the susceptibility of hepatocytes to immune mediated cell damage. These results do not support the concept that the agent exerts an effect either directly on the lymphocytes or by prevention of the interaction between the effector and antibody coated target cells.

The bioavailability of polyunsaturated phosphatidylcholine after oral administration has been 
shown by extensive studies in rats, dogs, and monkeys, with up to $50 \%$ of the drug being recovered from the thoracic duct. ${ }^{5}$ This has been confirmed in man, showing that after oral administration the radiolabelled agent is incorporated into the liver. ${ }^{6}{ }^{8}$ Furthermore, whole body autoradiographs in rats have shown that polyunsaturated phosphatidylcholine is predominantly transported to the liver. ${ }^{9}$ More importantly, it has been shown that orally administered, the agent is incorporated into rat liver membranes and this is associated with an alteration of the membrane. ${ }^{10}$ Such alterations in the lipids of the plasma membranes could effect effector cell target cell interaction, either directly or indirectly. For example, alteration of the lipid composition of immune lymphocytes and target cells inhibits conjugation between the two cell types. ${ }^{11}$ Membrane lipids have also been shown to be of importance in other cell to cell interactions. ${ }^{12}$ Indeed, it has been postulated that a specific effector cell to target cell binding is preceded by unstable and non-specific intercellular membrane interactions mediated through exposed cell surface membrane lipids. ${ }^{13}$

The failure of short term incubation of polyunsaturated phosphatidylcholine to modify the susceptibility of the hepatocytes to cell mediated cytotoxicity may be explicable for a number of reasons. Firstly, the incubation times may have been too short to allow incorporation of polyunsaturated phosphatidylcholine into the hepatocyte membrane. Secondly, the incorporation of polyunsaturated phosphatidylcholine into lipoprotein complexes and chylomicrons during absorption may have facilitated hepatic uptake of polyunsaturated phosphatidylcholine. Thus, polyunsaturated phosphatidylcholine may not exchange with cell phospholipids when presented directly to hepatocytes but would enter the liver incorporated in a chylomicron remnant.

Current therapy of $\mathrm{HBsAg}$ negative chronic active hepatitis is based on the use of corticosteroids, often in combination with azathioprine. Although good control can be obtained, attendant side effects can be severe, while in some cases, control is not obtained despite large doses of corticosteroids. Even in those cases where the disease appears to be well controlled, progression to cirrhosis may occur. ${ }^{14}$ The addition of polyunsaturated phosphatidylcholine to the therapeutic regime could therefore be of value as an adjunct to therapy allowing a reduction in the dose of corticosteroids. If the therapeutic mechanism of polyunsaturated phosphatidylcholine is by reducing the susceptibility of target hepatocytes to cell mediated damage, then its use may be beneficial in a number of other chronic liver disorders, such as alcoholic liver disease, in which immune mediated mechanisms may play an important role.

Dr $\mathrm{J}$ Neuberger is a Ciba-Geigy Research Fellow. We are grateful to Dr Ralph Kohn of Advisory Services (Clinical and General) Limited, London, for helpful advice and to Professor J Fox and Dr J Winkelman of Nattermann and $\mathrm{Cie} \mathrm{GmbH}$, Cologne, for the supply of polyunsaturated phosphatidylcholine.

\section{References}

1 Jenkins PJ, Portmann BP, Eddleston ALWF, Williams $R$. Use of polyunsaturated phosphatidylcholine in HBsAg negative chronic active hepatitis. Results of a prospective double blind controlled trial. Liver 1982; 2: $77-81$.

2 Wallnöfer H, Hanusch M. "Essential" phospholipids in the treatment of hepatic disease. Med Monatsschr 1973; 27: 331-6.

3 Cochrane AMG, Moussouros A, Thompson AD, Eddleston ALWF, Williams R. Antibody dependent cell mediated ( $\mathrm{K}$ cell) cytotoxicity against isolated hepatocytes in chronic active hepatitis. Lancet 1976; 1: 441-4.

4 Gonzales C, Cochrane AMG, Eddleston ALWF, Williams R. Mechanisms responsible for antibody dependent cell mediated cytotoxicity to isolated hepatocytes in chronic active hepatitis. Gut 1979; 20: 385-8.

5 Hegner D, Platt D. Effect of essential phospholipids on the properties of ATP-ases of isolated rat liver plasma membranes of young and old animals. Mechn Ageing Dev 1975; 4: 191-200.

6 Fox JM, Betzing H, Lekim D. Pharmacokinetics of orally ingested phosphatidylcholine. Nutr Brain 1979; 5: 95-108.

7 Anthony PP, Ishak KG, Nayak NC, Poulson HE, Scheuer PJ, Sobin IH. The morphology of cirrhosis. Recommendation of definition, nomenclature and classification by a working group sponsored by the World Health Organisation. J Clin Pathol 1978; 31: 395-414.

8 Zierenberg O, Grundy JM. Intestinal absorption of polyenephosphatidylcholine in man. J Lipid Res 1982; 23: 1136-42.

9 Lekim D. On the pharmacokinetics of orally applied essential phospholipids (EPL). In: Peeters, ed. Phosphatidylcholine. Berlin: Springer, 1976: 48-65.

10 Lekim D, Betzing H, Stoffel W. Incorporation of complete phospholipid molecules in cellular membranes of rat liver after uptake from blood serum. Hoppe Seylers Z Physiol Chem 1972; 353: 949-64.

11 Berke G, Tzur R, Inbar $M$. Changes in fluorescence polarisation of a membrane probe during lymphocyte target cell interaction. J Immunol 1978; 120: 1378-84. 
12 Humphries G, McConnell HM. Antigen mobility and complement mediated immune attack. Proc Natl Acad Sci 1975; 72: 2483-92.

13 Berke G. Interaction of cytotoxic $\mathrm{T}$ Lymphocytes and target cells. Prog Allergy 1980; 27: 69-133.
14 Kirk AP, Jain S, Pocock S, Thomas HC, Sherlock S. Later results of the Royal Free Hospital prospective controlled trial of prednisolone therapy in heaptitis B surface antigen negative chronic active hepatitis. Gut 1980; 21 : 78-83. 